\title{
ANALYZING THE POTENTIAL MECHANISM FOR MEASUREMENTS - THE MOST POPULAR OPEN SOURCE WEB CONTENT MANAGEMENT SYSTEM
}

\author{
Dejan Viduka ${ }^{1}$, \\ Ana Basic ${ }^{1}$, \\ Igor Lavrnic ${ }^{1}$ \\ ${ }^{1}$ Singidunum University, \\ Belgrade, Serbia
}

Correspondence:

Dejan Viduka

e-mail:

dejan@viduka.info

\begin{abstract}
:
The paper is dedicated to the analysis of the most popular Open Source Web Content Management System. The paper presents basic concepts and results of the gathered information related to participation of three the most popular systems, during period 2008 to 2011. Based on this information, the paper shows the trends in the development and popularity on the market. Through analysis of available information it has been proven, that the practice already knows, that the three most prominent systems are: Word Press, Joomla and Drupal, and exactly in that order in which they appear. Around the globe many researches has been conducted in order to find out which of these three systems is the best and why, but this question remains unanswered. We want to indicate in the paper that each of three systems is the best in its area of use, depending on the purpose and level of knowledge of the users.
\end{abstract}

\section{Keywords:}

Open Source, Web Content Management System, Word Press, Joomla, Drupal.

\section{INTRODUCTION}

Currently a lot of content management systems which are available to users are present on the market. Each of them has advantages and disadvantages in meeting client needs. Certain number of these products are launched on the market as open source software under GNU license [11]. This license allows increased flexibility and expandability. CMS is presenting a content management system which is covering all possible solutions allowing contents classification, organization, linkage of content and every other solution of content editing [10]. This term can be used for manual processes of content management although it is mostly implicating on various software solutions enabling advanced management of large number of information. The most present form of CMS implementation is on Internet known as WCMS (Web Content Management System). One of pioneer WCMS solutions was published under the name of Mambo, achieved great success due its using simplicity. Beside providing many advantages to webmasters, mambo often gives visitors opportunity to comment and mark the content which site gives more dynamics and interactivity [12],[14]. 


\section{WCMS - Web Content Management System}

WCMS (WCM or Web CMS) is CMS, which is launched as a web application, providing an option of easily creating and maintaining of HTML content. Moreover it is designed for maintaining large and dynamic HTML contents.

The basic functions are the following:
a) creating,
b) maintenance,
c) changes and
d) deletion.

WCMS is designed to meet the needs of beginners in web programming, allowing them to quickly and easily change the content of the web site. WCMS meets the challenge to be user friendly to administrators, who are not educated enough, technically, allowing them to develop web pages and organize presentations via WCMS without difficulties [2],[13].

\section{The term Open Source}

Currently there are two different interpretations: "Free Software" and "Open Source".

The term "Free Software" has root at GNU project and it could be defined as follows: free software is matter of choice not the price [15].

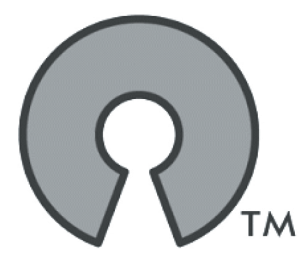

\section{open source}

Image 1. Official Open Source Logo

In order to understand this concept we should think in a way that "free" are like" freedom of speech" not like "free beer". Free of charge software is "users right to use the software, make a copy, distribute, change and eventually improve "issue". It is important to be mentioned that Open Source is not free of charge software nor only that its code is available to all users. Depending on the license under which software has been launched it gives us a wide scope of abilities of improvements and re-distribution under different name (fork) as well as free of charge using. Moreover the free use depends of license owners, some of them could be used only in private, and commercial use is not allowed by license owner. Finally there is a difference between Open Source and commercial software where the author is willing to make some profit, but in same time the commercial software could be "open code" like it is in case of PHP computer language use [12].

\section{THE ANALYSIS OF THE MOST POPULAR CMS SOLUTIONS}

The rapid expansion of CMS systems, both commercial and open source, has become a mystery which system is used more. In this paper we processed all available information about three leading open sources and providing data about them. One of the major CMS systems indicators of use and popularity level is the number of downloads, unfortunately this information is not a good bases for deep analyze and conclusions. Comparing the information we could note the following problematic reasons:

1. Data are not available on many systems

2. Measuring time of targeted groups of data varies

3. Some download sites presents statistics that are not gathered automatically

4. Web servers have an automatic package installation (Cpanel, plesk, fantastico)

5. The installation packages that are included in Linux distributions (Debrian or Gentoo) are also not included in this analysis

6. Rates of downloads are not constant over time (release of new version etc)

If we want to conduct deep analysis, we must take in consideration the possibility that information about the number of downloads, in following chart, are potentially inaccurate.

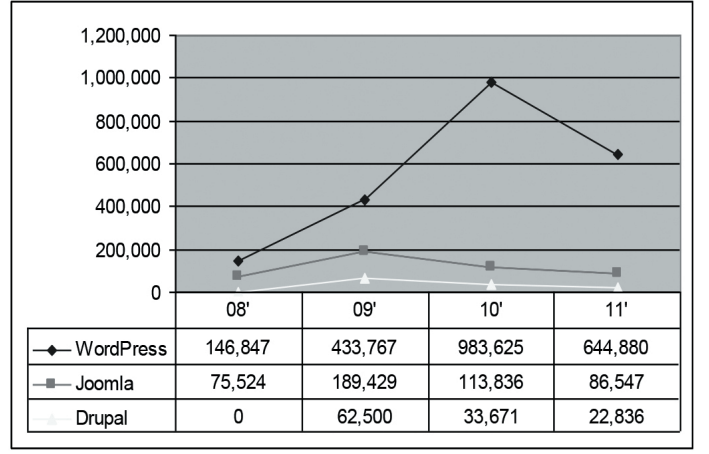

Fig. 1. Analysis of downloads for period 2008-2011. 
One of following topics, which could provide us with some information regarding the number of users, is support of the market and their participation in further development. In order to get adequate data, we will analyze following two groups:

\section{Developers}

2. Publishers

Above mentioned groups are the most eligible for analysis comparing to other available sources of information. In order to present precise information regarding developers and publishers, we took information about service development and demand from labor market for developers from two leading providers of online commercial services. The first provider is Elance and the second provider is Guru. In conducting deeper analyze of these systems we include the data regarding the number of professionals are offering their services in this area. Observing the chart that follows we could notice the difference in number of users per each system for targeted period of time 2008 to 2011.

The chart indicate the market demand for professional services in field of CMS systems, furthermore we must take in to consideration the fact that significant number of users independently develop their sites using CMS systems.

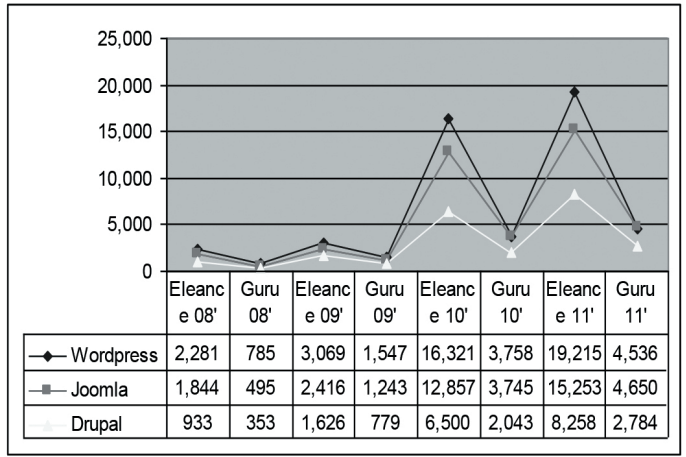

Fig. 2. Analysis of market demand for professional services 2008-2011.

Moreover, additional indicator of this thesis is the number of print publications related to this subject. Taking in consideration that publishers are guided with profitability, due to that, the publishing only issues with existing market demand. Having this fact, we believe that conducted analyze presents the market demand for CMS solutions, as well as the number of users, which are independently developing themselves, consequently decreasing the demand to professional assistance in the field of CMS systems and similar online systems.

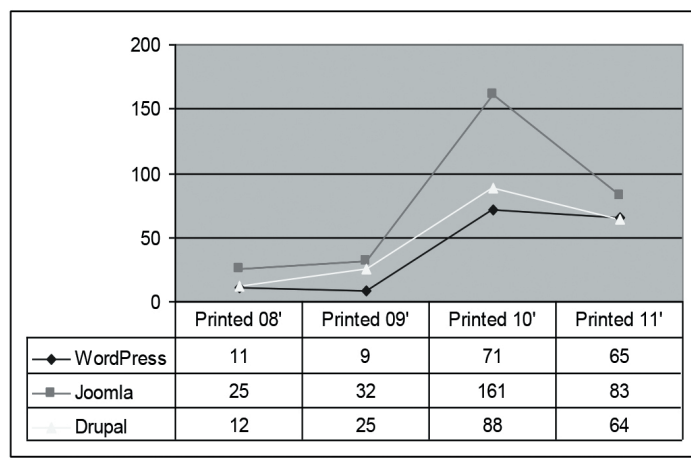

Fig. 3. Analyze of published edditions 2008-2011.

The chart above presents data regarding the number of published titles in connection with mentioned CMS systems. The source is Amazone site. The information is limited only to English printed editions, which could provide us the fact regarding popularity of mentioned CMS systems, that is presented in this paper. The last indicator we have used in this paper is strength of brand of mentioned CMS solutions. Measuring the strength of brand of Open Source product is quite challenge, it is not only due to the lack of maturity and commercial sophistication nor due to the non-existing simple method of determining the strength and popularity of above mentioned brands. As a solution to this problem we used Internet, trying to get information from large number of specimens. The data that follow in next chart are result of usage of site for online statistics - Alexa. Having a benefit of taking information from Alexa we are able to determine the popularity of domain, which is standing behind these three CMS. We must have in mind, like it was the case in previous analyzes, that this method is not $100 \%$ reliable, but still able to provide the data regarding correlation of popularity between these three systems [1],[5],[6],[7],[9],[13].

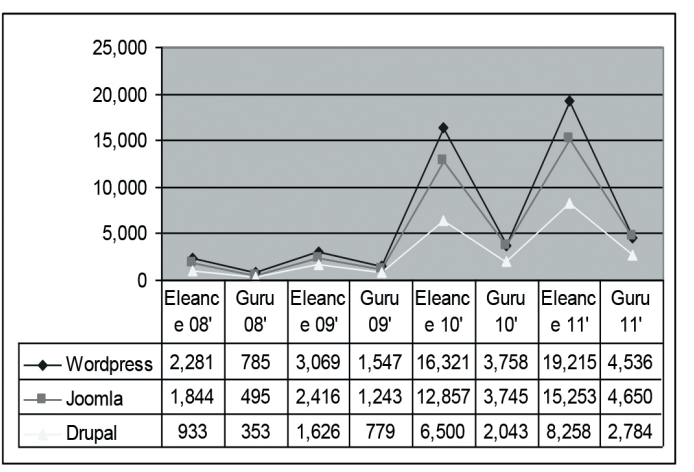

Figure 4: Alexa analyze, period 2008-2011. 


\section{DISCUSSION}

The first indicator in series of indicators that we have analyzed, is the number of downloads, beside the fact it is not reliable method, it indicates which one of three systems is the most used one, through analyzed period of time. Of course this is not valid indicator of level of usage, but definitely it presents the interest of the market at functional design of product and ability to be used for testing.

We must have on our mind that a lot of users download the installing software in order to test it, without intention to use it, in their site design. According to data of number of downloads (see Figure 1), we could notice that all three systems are declining lately (Wordpress has bigger drop than competitors), since this is not only indicator, in next chart (see Figure 2) information about labor market demand is presented, from two leading systems for mediating between demand and offer for job on internet, which give us a clear picture of how many job offers exist per each system. In this chart we can observe that Wordpress is an absolute leader during the targeted period of time which supports the data in first chart (see Figure 1). These two above mentioned indicators, clearly presents the volume of downloads per targeted system, as well as market demand of experts in this field. Moreover this data could give us a picture how many job opportunities are present on internet for someone who is expert in this field.

It is important to be mentioned that Drupal is mostly used by large number of professionals, which is supported with data presented in all charts in this paper; consequently there is lower demand for this profile experts. As it is explained with Drupal, there is also an explanation for leading CMS system in our analysis. Wordpress is leading system, supported with large number of users, which have a personal blogs or sites which are not extremely demanding. Charts also present Joomla as system which is in the middle, according to all indicators. Joomla also has significant demand on the market, mostly used for developing web pages of companies and more demanding projects, which is based on Joomla's user friendly features of the system [8],[10].

For the all analyzed systems a number of books and manuals was published, which helps users to overcome techniques how to use systems. Thanks to that, undoubtedly, we can see the support of wider community in the development of open source projects and what kind of future they have.
The last chart (see figure 4 and image 2) presents indicators of online systems for web statistics, which data are reliable as well as previous analysis, observing that this system is good for monitoring of these system over many years, taking in consideration the fact that Alexa is indexed based on same criteria.
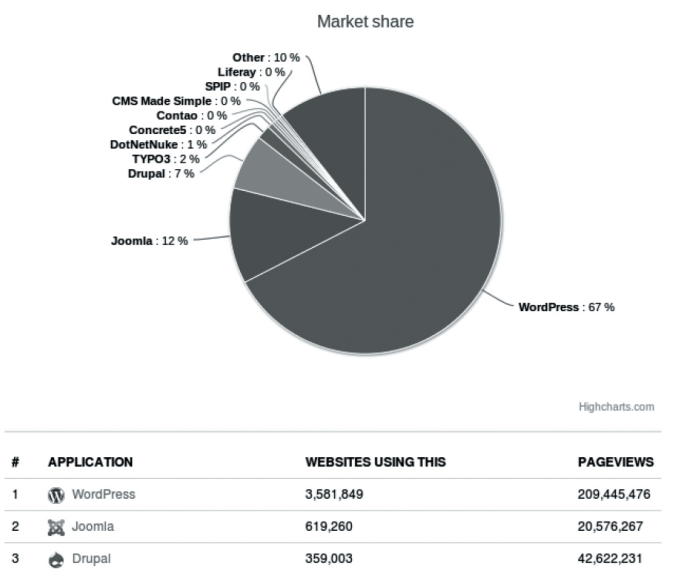

Image 2. Highcharts.com Statistic [3]

This chart supports other analysis which is indicating that Wordpress is leader against Joomla and Drupal. The index of these systems are constantly increasing which is leading us to suspect the validity of first chart (See Figure 1), which provides us a basis to made a conclusion that interest for these three systems is constantly dropping.

We must remind you, that all available information, that are processed and presented in charts, are not 100\% reliable, only alternative solution is to get more confidential sources and cross data to provide more reliable conclusion.

\section{CONCLUSION}

Content management systems (CMS - Content Management System) is software solution, which unlike traditional methods of content management, are more friendly using, in terms of knowledge requested and the time consumption. Currently there is a large number of CMS on the Internet, but it is difficult to make a choice and select the best one. Each system has his advantages and disadvantages, in another words they are more or less convenient to meet the task.

Some of systems have a great potential, but they are not user friendly, while others provide just basic elements of functionality with very user friendly features. Because of all above mentioned it is difficult to make a proper 
choice, and the best way is to define needs of the site and demands of persons who will develop the site and then make a proper choice.

Choosing CMS could be long and difficult process, especially due to the existence of large number of systems on the market. On site "Sourceforge.net" 600 active Open Source CMS projects are available [4].

The paper offers three solutions, based on popularity: 1) systems which are extremely user friendly for users with low knowledge and serious requests (leader Wordpress) 2) systems for semiprofessionals and more serious requests (leader Joomla) 3) systems which are meeting the request of professionals which are involved in challenging projects (leader Drupal).

The market already recognized order of popularity between three mentioned systems and it is as follows: Wordpress, Joomla and Drupal which is confirmed in the paper. All conducted analyses support this thesis. We regret the unavailability of data for 2012 - 2016 during the writing of the paper, because it would increase the level of reliability and timeliness of the paper.

\section{REFERENCES}

[1] Bonfield B. and Quinn L. S.: Comparing Open Source CMS: Joomla, Drupal and Plone: 2007.

[2] Karuovic D. and Radosav D., Managers' roles in web content management system, African Journal of Business Management Vol. 6(8), pp.2882-2887, 29 February, 2012.

[3] Official site: highcharts.com (2016).

[4] Official site: sourceforge.net (2014).
[5] Open Source CMS Market Share Report 2009, Published by Water\&Stone and CMSWire, 2009.

[6] Open Source CMS Market Share Report 2010, Published by Water\&Stone, 2010.

[7] Open Source CMS Market Share Report 2011, Published by Water\&Stone, 2011.

[8] Patel S. K., Rathod V. R. and Prajapati J. B., Performance Analysis of Content Management Systems- Joomla, Drupal and WordPress, International Journal of Computer Applications (0975 - 8887) Volume 21- No.4, May 2011.

[9] Shreves R.: The 2008 Open Source CMS Market Share Report, Published by Water\&Stone, 2008.

[10] Singhal N., Mohan T. and Sarkar S.: A Comparative Study Based on Open Source Content Management Systems: Indian Journal of Computer Science and Engineering: 2009.

[11] Viduka D. Possibilities of using Open Source software in the modern business: XII International Conference E-Commerce 2012, Palic, Serbia: 2012.

[12] Viduka D., Lavrnic I. and Basic A.: Comparative Study Based on Open Source Content Management Systems Mambo and his Fork - Joomla and Elxis: International Journal of Computer Science Issues, 2013.

[13] Viduka D., Analysis and Evaluation of Open Source Content Management Systems - CMS (WordPress, Joomla and Drupal), Master Thesis, Singidunum University. 2013.

[14] Vlahović V., System for Content Management, University of Zagreb, Faculty of electronic engineering and computer science, 2004.

[15] Yahya A. O.: Investigation, Installation and Implementation of an Open Source Content Management System: Technology and Communication: 2010. 